\title{
Introducción al dossier: Estudios del libro antiguo en América Latina: perspectivas, debates y problemas
}

Introdução ao dossiê: Estudos do livro antigo na América Latina: perspectivas, debates e problemas

\author{
Marina Garone Gravier \\ Universidad Nacional Autónoma de México. Instituto de \\ Investigaciones Bibliográficas. Seminario Interdisciplinario \\ de Bibliología, México \\ mgarone@unam.mx \\ iD https://orcid.org/0000-0002-5981-9243
}

Andre Vieira de Freitas Araujo

Universidade Federal do Rio de Janeiro. Faculdade

de Administração e Ciências Contábeis. Seminário

Internacional A Arte da Bibliografia, Brasil

armarius.araujo@gmail.com

iD https://orcid.org/0000-0002-3003-7424

Simbolismo y materialidad. Técnica y tecnología. Cultura y representación. Polisemia y ambigüedad. Palabras clave que apoyan la concepción, circulación y apropiación del libro antiguo. Sus teóricos tienden a situarlo entre los siglos XV y el XIX. Respecto a esta delimitación temporal, Martín Abad (2004) señala el problema de universalizar una cronología que no se construye de forma coincidente en varios países debido a sus características sociales, económicas, políticas y/o culturales.

Más allá de la dimensión cronológica, Pedraza, Clemente y de los Reyes (2003) señalan que el libro antiguo incluye objetos bibliográficos de variada configuración, que deben entenderse en un sentido amplio. Desde este punto de vista, el libro antiguo engloba los propios impresos antiguos, incluidos los incunables, pero también los manuscritos.

Como fuente y objeto para las ciencias y las artes, el libro antiguo integra diversos fondos antiguos en las bibliotecas del viejo mundo y también del nuevo, lo que nos permite identificar y analizar la temporalidad, la materialidad, la tecnología, el tratamiento documental y las mediaciones que han delineado y definido tanto al "libro antiguo" en sí como a las instituciones, los personajes y las comunidades que los custodian en el pasado y en el presente.

A través de la lente latinoamericana, es posible concebir observaciones y lecturas privilegiadas y particularizadas sobre el libro antiguo, ya que en este contexto lo sustentan dos pilares: 1) el desplazamiento y/o transitoriedad conceptual, cuando se lo compara con el concepto que se tiene de libro antiguo europeo; 2) la constitución de una "cosmología bibliográfica" genuinamente latinoamericana resultante de la amalgama y combinaciones variadas que se han dado tanto por los acervos bibliográficos europeos conservados en nuestro continente como de la integración de los acervos bibliográficos derivados de la propia producción tipográfica local.

Procuramos discutir algunas de las diversas variables en las que se desplaza, acciona, estudia y comprende el libro antiguo en nuestra región y presentamos, para reflexionar sobre el libro antiguo en el contexto 
latinoamericano, el dossier titulado "Estudios del libro antiguo en América Latina: perspectivas, debates, problemas".

Este dossier hemos querido reunir estudios sobre el libro antiguo en América Latina desde diferentes perspectivas, abordando debates y problemas actuales, para ello hemos considerado múltiples ejes de análisis y perspectivas: la interdisciplinaria, los personajes del libro, la materialidad del libro antiguo y su proceso productivo, su presencia en bibliotecas patrimoniales, su dimensión bibliográfica, perspectivas descoloniales, incluso preguntas sobre su organización y representación. Por ello hemos incluido estudios sobre libros antiguos o colecciones de libros antiguos producidos en América Latina o producidos en Europa, pero que se encuentran en acervos latinoamericanos, y que de alguna manera circularon en el continente. Entendemos por libro antiguo, impresos elaborados entre el siglo XV y el primer tercio del siglo XIX, es decir aquellos que fueron confeccionados con la tecnología manual. También nos referimos a manuscritos producidos antes de mediados del siglo XIX.

En busca de las particularidades del libro antiguo en el pasado y en el presente de América Latina, este dossier tiene como objetivo explicar algunos de los vínculos teóricos y metodológicos entre los innumerables aspectos que rodean al libro antiguo en su condición de objeto cultural.

Algunos de los ejes temáticos que propusimos fueron:

1. Cruces interdisciplinarios (historia, sociología, literatura, lingüística, estudios culturales, conservación, filología, etc.).

2. Personajes del libro (del autor al librero).

3. Materialidad y libro antiguo (cultura visual, edición, papel, técnicas de impresión, etc.).

4. El libro antiguo y su presencia en las bibliotecas patrimoniales (evolución, organización, y apropiación).

5. El libro antiguo y la bibliografía regional.

6. La mirada descolonial en los estudios del libro antiguo en América Latina.

7. El libro antiguo y la organización y representación de la información y el conocimiento.

Los ejes temáticos mencionados están presentes y se diluyen en el conjunto de seis contribuciones de autores de Argentina, Brasil, Colombia, Perú y México, según la secuencia que artículos y ensayos que aquí se presentan.

En el primer artículo "El libro antiguo y la reutilización de manuscritos: relevamiento, identificación y catalogación de fragmentos manuscritos in situ en colecciones argentinas" las investigadoras argentinas Marcela Borelli y Olga Soledad Bohdziewicz, ambas del Instituto de Investigaciones Bibliográficas y Crítica Textual, Universidad de Buenos Aires, proponen una aproximación al antiguo libro impreso existente en nuestras colecciones nacionales a través del examen de un aspecto hasta ahora poco estudiado: la presencia de fragmentos de manuscritos medievales y humanísticos empleados como refuerzos de diversa índole en las encuadernaciones, reconociendo su tipología a través del análisis de casos representativos. Su trabajo analiza una perspectiva de la materialidad muy novedosa en las colecciones latinoamericanas la "fragmentología", la cual, desde la perspectiva de la arqueología del libro antiguo en particular de las encuadernaciones permite vincular universos de la cultura escrita que se remontan a los manuscritos medievales y humanísticos y las colecciones regionales.

La segunda contribución del dossier es de la co-autoría de Andre Vieira de Freitas Araujo y Dina Marques Pereira Araujo, de las universidades Universidade Federal do Rio de Janeiro y Universidade Federal de Minas Gerais, respectivamente. En "Um catálogo beneditino em perspectiva bibliográfica: a representação documentária dos livros antigos da Biblioteca do Mosteiro de São Bento em São Paulo, Brasil (Sécs. XVXVIII)", en primer lugar los investigadores presentan y discuten el diseño, desarrollo y consolidación del Catálogo de Libros Antiguos de la Biblioteca del Monasterio de São Bento de São Paulo. El proyecto La Biblioteca inicia en 1598, y la colección contienen libros de los siglos XV al XVIII, de temáticas teológicas, 
históricas, filosóficas y de derecho canónico. Para analizar ese fondo, los autores inician con de las ideas sobre libros antiguos en el contexto regional latinoamericano y del Caribe. En un segundo lugar - y a partir de los inventarios y la articulación de una base de datos exponen la organización de la información de 581 libros antiguos. A partir del estudio de un acervo concreto-, el ensayo aporta conocimientos para la bibliotecología, la historia del libro, la lectura y las bibliotecas en Brasil, desde las perspectivas de la biblioteca monástica benedictina en su dimensión histórica y patrimonial. El ejercicio de bibliografía histórica que los autores llevaron a cabo busca atravesar y, a la vez, dilatar la dimensión instrumental y funcional del catálogo, en la medida en que corresponde a un recorrido histórico de concepción y reflexión de y sobre los productos documentales que demarcaron y demarcan la cultura monástica benedictina.

La profesora de la Universidad “Jorge Tadeo Lozano”, Claudia Angélica Reyes Sarmiento, ofrece la tercera contribución del dossier en el artículo "Imprentas e impresores: libro antiguo, Orden de Predicadores”. El objetivo central es describir y caracterizar los libros con que cuenta la Colección de la Orden de Predicadores, de la Biblioteca del Convento de Santo Domingo de Guzmán, de la ciudad de Tunja (Boyacá, Colombia). La colección empezó a conformarse en 1550 y está compuesta por 6.000 volúmenes del período antiguo, de los cuales 980 fueron impresos en España. Para describir esos libros se analizaron sus elementos materiales y de diseño como: tipos de letras, composición, tamaños, formatos, colores, imágenes, soportes, clases de encuadernación, marcas de impresor, marcas tipográficas, rastros del lector, signaturas, unicidad, etc.; además de los del asiento bibliográfico clásico, en este trabajo se empleó una muestra de 52 impresos. Este artículo presenta las ricas interacciones que puede ofrece en análisis cruzado del libro antiguo y el diseño gráfico de un conjunto bibliográfico patrimonial concreto.

En el ensayo "Os catálogos oitocentistas do Curso de Sciencias Juridicas e Sociaes em Olinda e Recife”, escrito en co-autoría por Gilda Maria Whitaker Verri y Karine Gomes Falcão Vilela, ambas de la Universidade Federal de Pernambuco, es trae la cuarta perspectiva en la que se analiza el caso de la biblioteca que se conformó, a partir de las colecciones adquiridas, para ser usada en el Curso de Ciencias Jurídicas y Sociedades en Olinda, en Brasil. El objetivo principal de las autoras ha sido comprender y demostrar los alcances y las características de la organización bibliográfica en el proceso original de conformación de la colección y para ello se valieron de distintas fuentes como listas manuscritas, inventarios y catálogos de época. La perspectiva empleada en este trabajo será la bibliografía histórica, la ciencia de la información y el enfoque epistemológico a partir de los cuáles se llega a las conclusiones sobre la práctica de la organización bibliográfica en un momento histórico determinado.

Pedro M. Guibovich Pérez, académico de la Pontificia Universidad Católica del Perú, nos ofrece el quinto ensayo del dossier, titulado "La fundación de la Biblioteca Nacional del Perú en 1821", el cual pone de manifiesto la importancia histórica y cultura que implicó justamente el inicio de la vida institucional de ese repositorio de alcance nacional. El surgimiento de ese espacio de memoria del naciente nuevo estado peruano después de la proclamación de su independencia por el general José de San Martín en 1821, tiene además de una dimensión institucional una de orden simbólico: ya que de algún modo el pensamiento y acción que se tuvo sobre el acervo y los fondos del pasado implicaron un proceso de ruptura con el régimen colonial.

Javier Eduardo Ramírez López, estudiante doctoral de El Colegio de México, pone el acento en el estudio de manuscritos antiguos, en la sexta y última contribución del número que hemos preparado. En "El Códice Cardona: un acercamiento a la materialidad y contenido de un documento desconocido" se centra en el análisis de tres páginas de la "Relación del señorío de Xochimilco y la república de indios de Chalco" que está ambientada en México en la década de 1550. Uno de los puntos sensibles del análisis es que de dicha relación no se conoce un original del siglo XVI, por lo cual la información contenida en el Códice Cardona presenta semejanza con otros documentos, es esa semejanza gráfica y otros aspectos de la materialidad del documento, los que son analizados por el investigador.

Estas contribuciones, miradas en conjunto, si bien no abarcan la totalidad de las experiencias del libro antiguo en América Latina, en cambio esbozan un panorama significativo y actual sobre sus perspectivas, 
debates y problemas, en la medida en que plantean una serie de interrogantes sobre los horizontes teóricos y metodológicos que anclan la investigación que ha manifestado una actividad creciente e incesante en la región.

Con esta publicación, hemos querido crear un espacio de encuentro interdisciplinario entre los académicos interesados en los libros, tanto en su sentido de fuente como de objeto de investigación. Este dossier también se justifica por la necesidad, histórica y epistemológicamente, de (re)posicionar el libro antiguo, especialmente en tiempos de tensión económica y social, las discusiones sobre el papel y el lugar del patrimonio y la memoria y, aún, de las demandas de identidad en el territorio bibliográfico encantador, poderoso y complejo que es nuestra América Latina.

\section{Introdução ao dossiê: Estudos do livro antigo na América Latina: Perspectivas, DEBATES E PROBLEMAS}

Simbolismo e materialidade. Técnica e tecnologia. Cultura e representação. Polissemia e ambiguidade. Palavras-chave que sustentam a concepção, circulação e apropriação do livro antigo. Os teóricos do livro antigo tendem a situá-lo entre os séculos XV e XIX. Em relação a esta delimitação temporal, Martín Abad (2004) assinala o problema de universalizar uma cronologia que não se constrói de forma coincidente em vários países em função de suas características sociais, econômicas, políticas e/ou culturais.

Para além da dimensão cronológica, Pedraza, Clemente e Fermín de los Reyes (2003) indicam que o livro antigo contempla objetos bibliográficos de configurações variadas, que devem ser compreendidos em sentido amplo. Neste ponto de vista, o livro antigo abarca os próprios impressos antigos, incluindo incunábulos, mas também os manuscritos.

Como fonte e objeto para as ciências e as artes, o livro antigo integra diversos fundos antigos em bibliotecas do velho mundo e também do novo, o que nos permite identificar e analisar a temporalidade, materialidade, tecnologia, tratamento documental e mediações que delinearam e definiram tanto o "livro antigo" em si como as instituições, personagens e comunidades que o salvaguardam no passado e no presente.

Através da lente latino-americana, é possível conceber observações e leituras privilegiadas e particularizadas sobre o livro antigo, já que neste contexto o sustentam dois pilares: 1) o deslocamento e/ou transitoriedade conceitual, quando comparado ao conceito de livro antigo europeu; 2) a constituição de uma "cosmologia bibliográfica" genuinamente latino-americana resultante do amálgama e combinações variadas que tanto têm sido dadas pelas coleções bibliográficas europeias conservadas em nosso continente bem como a integração de acervos bibliográficos derivados da própria produção tipográfica local.

Com o propósito de discutir algumas das diversas variáveis nas quais se move, opera, estuda e compreende o livro antigo em nossa região e com o objetivo de também refletir sobre o livro antigo no contexto latinoamericano, apresentamos o dossiê intitulado "Estudos do livro antigo da América Latina: perspectivas, debates, problemas".

Neste dossiê queríamos reunir estudos sobre o livro antigo na América Latina a partir de diferentes perspectivas, abordando os debates e problemas atuais, para isso consideramos múltiplos eixos de análise e perspectivas: a interdisciplinaridade, os personagens do livro, materialidade do livro antigo e seu processo de produção, sua presença em bibliotecas patrimoniais, sua dimensão bibliográfica, perspectivas decoloniais, incluindo questões sobre sua organização e representação. Por este motivo, incluímos estudos sobre livros antigos ou coleções de livros antigos produzidos na América Latina ou produzidos na Europa, mas que se encontram em acervos latino-americanos, e que de alguma maneira circularam no continente. Entendemos por livro antigo, impressos elaborados entre o século XV e o primeiro terço do século XIX, ou seja, aqueles que foram confeccionados com a tecnologia manual. Também nos referimos a manuscritos produzidos antes de meados do século XIX. 
Alguns dos eixos temáticos que propusemos foram:

1. Cruzamentos interdisciplinares (história, sociologia, literatura, linguística, estudos culturais, conservação, filologia, etc.).

2. Personagens do livro (do autor ao livreiro).

3. Materialidade e livro antigo (cultura visual, edição, papel, técnicas de impressão, etc.).

4. O livro antigo e sua presença nas bibliotecas patrimoniais (evolução, organização, e apropriação).

5. O livro antigo e a bibliografia regional.

6. A perspectiva decolonial nos estudos do livro antigo na América Latina.

7. O livro antigo e a organização e representação da informação e do conhecimento.

Os eixos temáticos supramencionados estão presentes e se diluem em um conjunto de seis contribuições de autores da Argentina, Brasil, Colômbia, Perú, e México, de acordo com a sequência de artigos e de ensaios que aqui apresentamos.

No primeiro artigo, "El libro antiguo y la reutilización de manuscritos: relevamiento, identificación y catalogación de fragmentos manuscritos in situ en colecciones argentinas", as pesquisadoras argentinas Marcela Borelli e Olga Soledad Bohdziewicz, ambas do Instituto de Investigaciones Bibliográficas y Crítica Textual, Universidad de Buenos Aires, propõem uma abordagem ao antigo livro impresso existente em nossas coleções nacionais através do exame de um aspecto até agora pouco estudado: a presença de fragmentos de manuscritos medievais e humanísticos usados como reforços de vários tipos nas encadernações, reconhecendo sua tipologia através da análise de casos representativos. Seu trabalho analisa uma perspectiva da materialidade muito nova nas coleções latino-americanas, a "fragmentologia", que, do ponto de vista da arqueologia do livro antigo, em particular das encadernações, permite conectar universos da cultura escrita que remontam aos manuscritos medievais e humanísticos e às coleções regionais.

A segunda contribuição do dossiê é da coautoria dos doutores Andre Vieira de Freitas Araujo e Dina Marques Pereira Araujo, da Universidade Federal do Rio de Janeiro e da Universidade Federal de Minas Gerais, respectivamente. Em "Um catálogo beneditino em perspectiva bibliográfica: a representação documentária dos livros antigos da Biblioteca do Mosteiro de São Bento em São Paulo, Brasil (Sécs. XV-XVIII)", os pesquisadores, no primeiro lugar, apresentam e discutem o desenho, desenvolvimento e consolidação do Catálogo de Livros Antigos da Biblioteca do Mosteiro de São Bento de São Paulo. O projeto da Biblioteca teve início em 1598, e o acervo contém livros dos séculos XV ao XVIII, sobre temas teológicos, históricos, filosóficos e de direito canônico. Para analisar esse fundo bibliográfico, os autores partem de ideias sobre os livros antigos no contexto regional da América Latina e do Caribe. Em segundo lugar - e a partir dos inventários e da articulação de um banco de dados, expõem a organização da informação de 581 livros antigos. A partir do estudo de um acervo específico, o ensaio traz conhecimento para a biblioteconomia, a história do livro, da leitura e das bibliotecas no Brasil, na perspectiva da biblioteca monástica beneditina em sua dimensão histórica e patrimonial. O exercício de bibliografia histórica que os autores realizaram procura atravessar e, ao mesmo tempo, dilatar a dimensão instrumental e funcional do catálogo, na medida em que corresponde a um percurso histórico de concepção e reflexão de e sobre os produtos documentários que demarcaram e demarcam a cultura monástica beneditina.

A professora da Universidad "Jorge Tadeo Lozano", Claudia Angélica Reyes Sarmiento, oferece a terceira contribuição do dossiê no artigo "Imprentas e impresores: libro antiguo, Orden de Predicadores". O objetivo principal foi descrever e caracterizar os livros da Coleção da Ordem dos Pregadores, da Biblioteca do Convento de Santo Domingo de Guzmán, da cidade de Tunja (Boyacá, Colômbia). A coleção começou a se formar em 1550 e é composta por 6.000 volumes do período antigo, dos quais 980 foram impressos na 
Espanha. Para descrever esses livros, foram analisados seus elementos materiais e de design, tais como: tipos de letra, composição, tamanhos, formatos, cores, imagens, suportes, tipos de encadernação, marcas de impressor, marcas tipográficas, vestígios do leitor, assinaturas, unicidade, etc.; além das bases bibliográficas clássicas, neste trabalho foi utilizada uma amostra de 52 impressos. Este artigo apresenta as ricas interações que pode oferecer na análise cruzada do livro antigo e o design gráfico de um conjunto bibliográfico patrimonial concreto.

O ensaio "Os catálogos oitocentistas do Curso de Sciencias Juridicas e Sociaes em Olinda e Recife", escrito em coautoria por Gilda Maria Whitaker Verri e Karine Gomes Falcão Vilela, ambas da Universidade Federal de Pernambuco, traz a quarta perspectiva na qual se analisa o caso da biblioteca que se formou, a partir dos acervos adquiridos, para ser utilizada no Curso de Sciencias Juridicas e Sociaes em Olinda e Recife, no Brasil. O principal objetivo das autoras foi compreender e demonstrar o alcance e as características da organização bibliográfica no processo original de formação do acervo e, para isso, utilizaram diferentes fontes como listas manuscritas, inventários e catálogos da época. A perspectiva utilizada neste trabalho foi a Bibliografia Histórica, a Ciência da Informação e a abordagem epistemológica a partir da qual se chega a conclusões sobre a prática de organização bibliográfica em um dado momento histórico.

Pedro M. Guibovich Pérez, acadêmico da Pontificia Universidad Católica del Perú, nos oferece o quinto ensaio do dossiê, intitulado "La fundación de la Biblioteca Nacional del Perú en 1821", que destaca a importância histórica e cultural que implicou justamente o início da vida institucional deste repositório de âmbito nacional. O surgimento deste espaço de memória do nascente novo estado peruano, após a proclamação de sua independência pelo General José de San Martín em 1821, tem além de uma dimensão institucional, uma de ordem simbólica: pois de alguma forma o pensamento e a ação que se teve sobre o acervo e os fundos do passado implicaram um processo de ruptura com o regime colonial.

Javier Eduardo Ramírez López, doutorando do El Colegio de México, destaca o estudo dos manuscritos antigos, na sexta e última contribuição do número que preparamos. Em "El Códice Cardona: un acercamiento a la materialidad y contenido de un documento desconocido", Ramírez López enfoca a análise de três páginas da "Relación del señorío de Xochimilco y la república de indios de Chalco" que está ambientada no México na década de 1550. Um dos pontos sensíveis da análise é que não se conhece nenhum original do século XVI desta relação, razão pela qual as informações contidas no Códice Cardona apresentam semelhança com outros documentos, é essa semelhança gráfica e outros aspectos da materialidade do documento que são analisados pelo pesquisador.

Essas contribuições, tomadas em conjunto, embora não abranjam a totalidade das experiências do livro antigo na América Latina, por outro lado, traçam um panorama significativo e atual sobre suas perspectivas, debates e problemas, na medida em que levantam uma série de questionamentos sobre os horizontes teóricos e metodológicos que ancoram as pesquisas crescentes e incessantes na região.

Com esta publicação, desejamos criar um espaço de encontro interdisciplinar entre diferentes acadêmicos interessados nos livros, tanto em seu sentido de fonte como de objeto de investigação. Este dossiê também se justifica pela necessidade de (re)posicionar, histórica e epistemologicamente, o livro antigo, especialmente em tempos de tensão econômica e social, de discussóes sobre o papel e o lugar do patrimônio e memória e, ainda, de reivindicações identitárias no território bibliograficamente encantador, potente e complexo que é a nossa América Latina.

\section{REFERENCIAS}

Martin Abad, J. (2004). Los libros impresos antiguos. Valladolid: Universidad de Valladolid, Secretariado de Publicaciones e Intercambio Editorial.

Pedraza García, M. J.; Clemente San Román, Y. y Reyes Gómez, F. (2003). El libro antiguo. Madrid: Síntesis. 